\title{
Oxidative stress in epileptic patients on different antiepileptic monotherapy
}

\author{
Imad A.J. Thanoon \\ Department of Pharmacology, College of Medicine - University of Mosul
}

(Ann. Coll. Med. Mosul 2007; 33(1\&2):35-41)

Received: $24^{\text {th }}$ Jul 2006; Accepted: $10^{\text {th }}$ Sept 2007

\begin{abstract}
:
Objective: To assess, the oxidative stress (by assessing lipid peroxidation) and total antioxidant status, in epileptic patients on different antiepileptic monotherapy (carbamazepine (CBZ), valproic acid (VPA) or Phenobarbital (PhB)), in comparison with the control.

Methods: This case-control study was conducted in the department of pharmacology- College of Medicine -University of Mosul from the $1^{\text {st }}$ of June 2005 to the $15^{\text {th }}$ of June 2006. A total of seventy four epileptic patients, on different antiepileptic monotherapy were included 38 on carbamazepine, 23 on valproic acid and 13 on phenobarbital, with 40 apparently healthy subjects as a control group for patients on carbamazepine or valproic acid and with 15 healthy children as a control group for patients on phenobarbital. For each patient and control subject, serum malondialdehyde (MDA) which reflects the lipid peroxidation, and total antioxidant status (TAS) were measured.

Results: There was a significant increase in serum MAD level and a significant decrease in serum TAS level in epileptic patients on different antiepileptic monotherapy (CBZ, VPA and $\mathrm{PhB}$ ).

With the exception of patients on $\mathrm{PhB}$, there was a poor correlation between MDA, TAS, the age of patients, the duration of illness and the duration of therapy.

Conclusion: Epileptic patients on CBZ, VPA and PhB monotherapy had elevated lipid peroxidation as reflected by a significant increase in serum MDA and a decrease in serum TAS level, which might reflect a great impact on oxidative /antioxidant status.
\end{abstract}

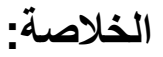

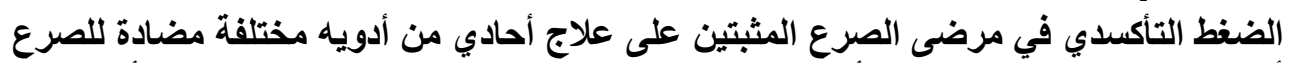

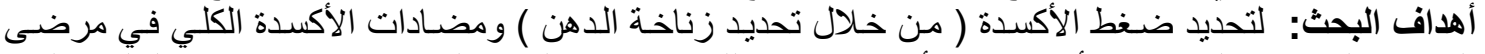

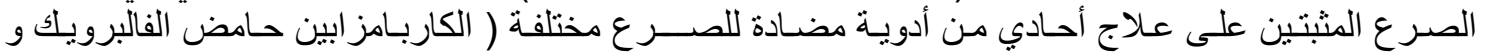
الفينوباربيتال) بالمقارنة مع المجموعة الضين الضابطة.

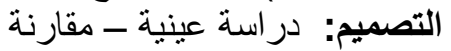

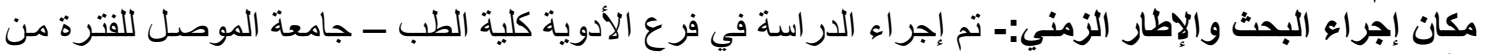

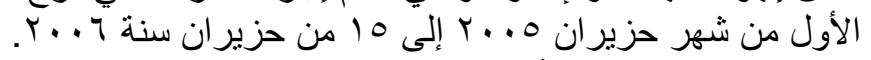

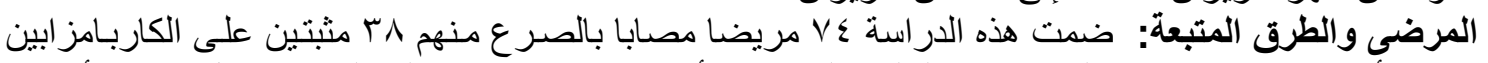

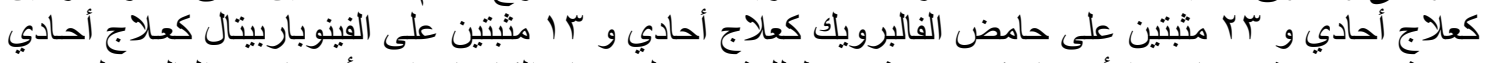

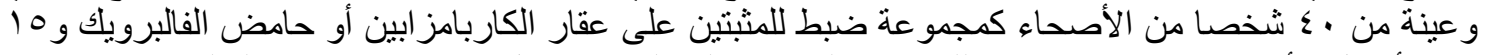

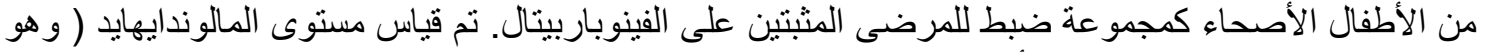

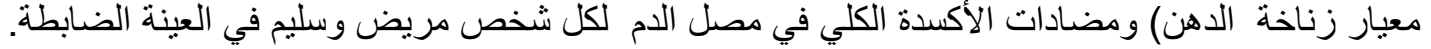

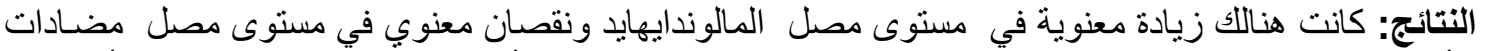

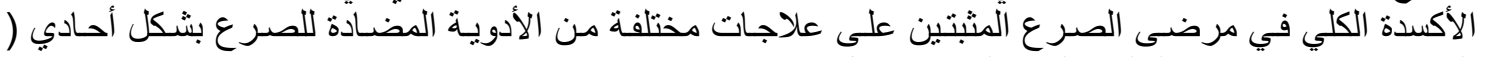

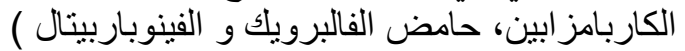

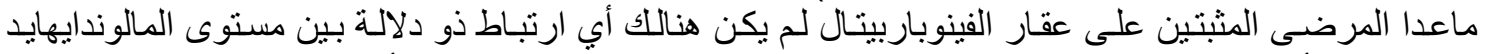

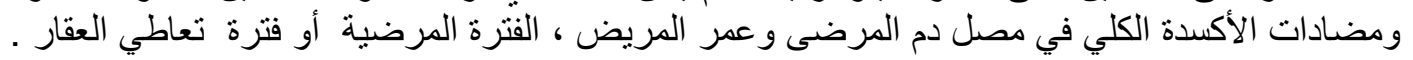




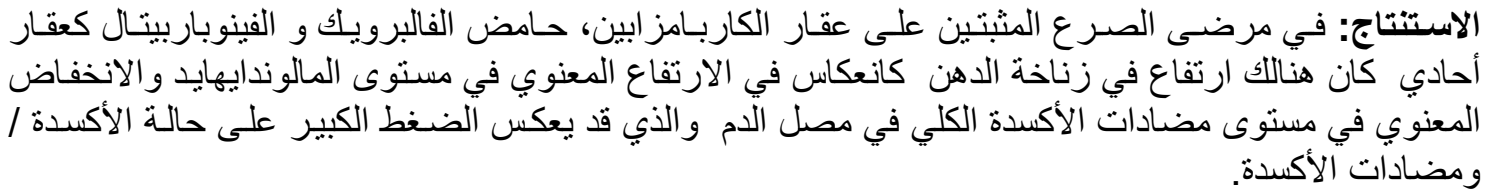

$\mathrm{E}$ pilepsy is a chronic dynamic important medical problem ${ }^{(1)}$. It has been reported that increased generation of free radicals or reduced activity of antioxidant defense mechanisms can cause some forms of seizures and in addition increases the risk of seizure recurrence. Peroxidation of membrane lipids caused by an increased generation of free radicals or decrease in the activities of antioxidant defense systems have been suggested to be critically involved in seizure control ${ }^{(2)}$.

Many antiepileptic drugs are metabolized to generate reactive metabolites with the capacity of covalent binding to macromolecules as protein or other vital biomolecules and hence inducing systemic toxicity ${ }^{(3)}$.

Malondialdehyde (MDA) is one of the important aldehydes resulting from membrane lipid peroxidation. Free radical scavenging activity was indicated by the total antioxidant system. It has been suggested that antiepileptic drugs have occasionally been associated with significant adverse effects on the antioxidant defense system $^{(4)}$. The available information regarding the effect of certain antiepileptic drugs on free radical/antioxidant status is poor. Therefore, this study aimed to evaluate the lipid peroxidation and total antioxidant status in epileptic patients on different antiepileptic monotherapy (carbamazepine (CBZ), valproic acid (VPA) and phenobarbital( $\mathrm{PhB})$ ).

\section{Subjects and Methods:}

Out of 93 epileptic patients, referred from the outpatient clinic, only 74 , fullfield the following selection criteria and included in the study;

1. Epileptic patients were diagnosed by neurologist.

2. On antiepileptic monotherapy for a duration of not less than 1 year.

3. No other cardiovascular, respiratory, renal, hepatic diseases or DM.

4. Not smokers neither alcohol drinkers.

5. No other medication received beside the antiepileptic therapy.
Those who met the criteria include, 38 patients on CBZ monotherapy: they were 28 males and 10 females with a mean \pm SD age of $30.02 \pm 7.73$ years (ranged between 18 and 45 years), with a mean $\pm S D$ duration of illness of $6.47 \pm 3.30$ year (ranged between 1 and 12 years). The mean \pm SD duration of treatment with CBZ of $4.21 \pm 3.09$ years (ranged between 1 and 12 years). They were on CBZ in a daily dose of $600 \mathrm{mg}$ in three divided doses.

Twenty three patients on VPA monotherapy were also included. They were 20 males and 3 females, with a mean \pm SD age of $28 \pm 7.34$ years (ranged between 18 and 45 years), with a mean \pm SD duration of illness of $5.82 \pm 3.92$ year (ranged between 1 and 15 years) and a mean \pm SD duration of treatment with VPA monotherapy of $3.91 \pm 2.96$ years (ranged between 1 and 10 years). They were on VPA monotherapy in a daily dose of 400 $\mathrm{mg}$ in 2 divided doses.

Thirteen epileptic patients on PhB. monotherapy were also included. They were 10 males and 3 females, with a mean $\pm S D$ age of $11.07 \pm 2.13$ year (ranged between 9 and 15 years), with a mean \pm SD duration of illness of $2.30 \pm 1.31$ years (ranged between 1 and 5 years) and a mean $\pm S D$ duration of monotherapy of $2 \pm 1.15$ years (ranged between 1 and 5 years). he mean daily dose of $129.23+22.53 \mathrm{mg}$ and ranged between 120 and $180 \mathrm{mg}$ daily.

\section{Control sample was divided into two groups}

1. Group 1:

Included 40 apparently healthy subjects. They were 31 males and 9 females with a mean \pm SD age of 29.72 \pm 7.33 year (ranged between 18 and 45 year) taken as a control group for patients on CBZ or VPA monotherapy .

\section{Group 2:}

Included 15 apparently healthy children. They were 12 males and 3 females with a mean \pm SD age of $10.73 \pm 2.31$ year ( ranged between 7 and 15 year ) taken as a control group for patients on $\mathrm{PhB}$ monotherapy. 
Concentration of serum MDA was measured by the method of Buege AND Aust $(1978)^{(5)}$. Measurement of serum total antioxidant status (TAS): Peroxidase / $\mathrm{H} 2 \mathrm{O} 2$ IABTS colorimetric assay ${ }^{(6)}$, using a kit purchased from Rondox Company UK. Data analysis were made using standard statistical method to determine the mean, standard deviation (SD) and the range. Unpaired Z-test and unpaired t-test were needed to compare the results of various parameters among antiepileptic cases and controls. Linear regression analysis; (Pearson's correlation coefficient (r)) was performed to assess the degree of association between different parameters.

\section{Results:}

There was a highly significant difference in the mean serum level of MDA between patients on CBZ and the control group $(p<$ $0.001)$. A highly significant difference in the mean serum level of TAS $(P<0.001)$ was found (Table1). There was a highly significant difference in the mean serum level of MDA and TAS between patients on VPA and the control group ( $<<0.001 ; p<$ 0.001 , respectively) (Table 2 ). There was a highly significant difference in the mean serum level of MDA and TAS between patients on $\mathrm{PhB}$ and the control group $(\mathrm{p}<$ $0.001 ; p=0.001$, respectively) (Table 3 ). Comparing the serum levels of MDA and TAS in patients on different antiepileptic drugs, there was a significant difference $(p \leq$ 0.05 ) between serum levels of MDA in patients on VPA and its level in patients on CBZ or PhB monotherapy. A significant difference was found between patients on CBZ monotherapy and those on VPA or Ph $B$, with regard to serum TAS level (Table 4).
There was a poor correlation between age of patients with MDA and TAS $(r=$ $0.0179 ; \quad p>0.05) \quad(r=0.05 ; \quad p>0.05)$, respectively. There was also a poor correlation between MDA and TAS level and the duration of illness $(r=-0.17 ; p>$ $0.05)(r=0.022 ; p>0.05)$, respectively. A poor correlation was also demonstrated between MDA and TAS serum level and the duration of treatment with CBZ $(r=-0.05, p>$ $0.05 ; r=-0.11, p>0.05$ ), respectively.

There was a poor correlation between serum level of MDA and TAS and the age of patients on VPA monotherapy ( $r=-0.11$; $p>0.05) \quad(r=0.26 ; \quad p>0.05)$, respectively. Regarding the relationship between serum level MDA and TAS and the duration of illness, a poor correlation has been demonstrated in this study $(r=-0.21$, $p>0.05)(r=0.17, p>0.05)$, respectively. Also a poor correlation has been demonstrated between serum level of MDA and TAS and duration of therapy with VPA monotherapy $(r=-0.19, \quad p>0.05) \quad(r=0.15, \quad p>0.05)$, respectively.

There was a poor correlation between serum MDA level and age of patients on $\mathrm{Ph}$ B monotherapy $(r=0.18 ; p>0.05)$. With a significant correlation existing between serum level of TAS and age of the patients $(r=0.64 ; p<0.05)$ (figure 1). A significant correlation was found between MDA and the duration of illness $(r=0.57 ; p<0.05)$ (figure 2).A poor correlation between serum level of TAS and duration of illness existed $(r=0.31, p>0.05)$. A significant correlation was found between serum level of MDA and the duration of therapy with $\mathrm{PhB}$ monotherapy $(r=0.61, p<0.05)$ (figure 3$)$, while a poor correlation between serum level of TAS serum level and duration of therapy $(r=0.32, p>0.05)$.

Table(1) Comparison of studied parameters between control and patients on CBZ therapy.

\begin{tabular}{||l|c|c|c||}
\hline \multirow{2}{*}{ Parameters } & \multicolumn{2}{|c|}{ Mean \pm SD } & \multirow{2}{*}{ p-value } \\
\cline { 2 - 4 } & $\begin{array}{c}\text { Control } \\
(\mathbf{n}=\mathbf{4 0})\end{array}$ & $\begin{array}{c}\text { Patients } \\
(\mathbf{n}=\mathbf{3 8})\end{array}$ & $<0.001$ \\
\hline MDA $(\mathrm{mg} / \mathrm{l})$ & $1.20 \pm 0.33$ & $1.85 \pm 0.60$ & $<0.001$ \\
\hline TAS $(\mu \mathrm{mol} / \mathrm{l})$ & $1.58 \pm 0.14$ & $1.17 \pm 0.26$ & $<$ \\
\hline
\end{tabular}


Table(2) Comparison of studied parameters between control and patients on VPA therapy.

\begin{tabular}{||l|c|c|c||}
\hline \hline \multirow{2}{*}{ Parameters } & \multicolumn{2}{|c|}{ Mean \pm SD } & \multirow{2}{*}{ p-value } \\
\cline { 2 - 4 } & $\begin{array}{c}\text { Control } \\
(\mathbf{n = 4 0 )}\end{array}$ & $\begin{array}{c}\text { Patients } \\
(\mathbf{n}=\mathbf{2 3})\end{array}$ & $<0.001$ \\
\hline MDA $(\mathrm{mg} / \mathrm{l})$ & $1.20 \pm 0.33$ & $2.25 \pm 0.52$ & $<0.001$ \\
\hline TAS $(\mu \mathrm{mol} / \mathrm{l})$ & $1.58 \pm 0.14$ & $1.01 \pm 0.21$ & $<$ \\
\hline
\end{tabular}

Table (3) Comparison of studied parameters between control and patients on PhB therapy

\begin{tabular}{|c|c|c|c|}
\hline \multirow[b]{2}{*}{ Parameters } & \multicolumn{2}{|c|}{ Mean \pm SD } & \multirow[b]{2}{*}{$p$-value } \\
\hline & $\begin{array}{l}\text { Control } \\
(\mathrm{n}=15)\end{array}$ & $\begin{array}{c}\text { Patients } \\
(n=13)\end{array}$ & \\
\hline MDA (mg/l) & $1.13 \pm 0.20$ & $1.84 \pm 0.60$ & $<0.001$ \\
\hline TAS $(\mu \mathrm{mol} / \mathrm{l})$ & $1.52 \pm 0.14$ & $1.02 \pm 0.21$ & 0.001 \\
\hline
\end{tabular}

Table (4) Comparison of studied parameters between patients on different drugs.

\begin{tabular}{||l|c|c||}
\hline \hline \multirow{2}{*}{ Parameters } & \multicolumn{2}{|c||}{ Mean \pm SD } \\
\cline { 2 - 3 } & MDA (mg/l) & TAS (umol/l) \\
\hline CBZ & $1.85 \pm 0.60 \mathrm{a}$ & $1.17 \pm 0.26 \mathrm{~b}$ \\
\hline VPA & $2.25 \pm 0.52 \mathrm{~b}$ & $1.01 \pm 0.21 \mathrm{a}$ \\
\hline Ph.B & $1.84 \pm 0.60 \mathrm{a}$ & $1.02 \pm 0.21 \mathrm{a}$ \\
\hline
\end{tabular}

Means with different letters vertically have significant difference at $p \leq 0.05$

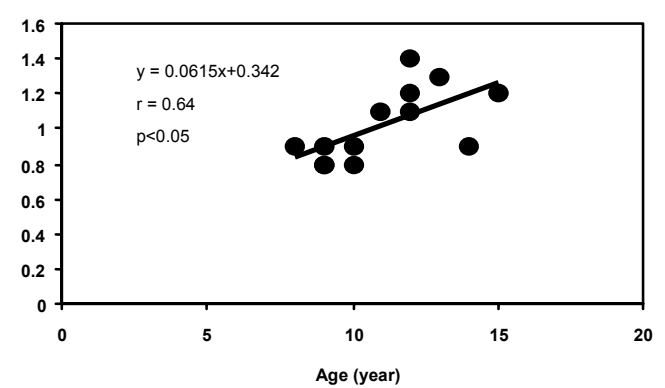

Fig. (1) Relationship between age and TAS in patients on PhB therapy

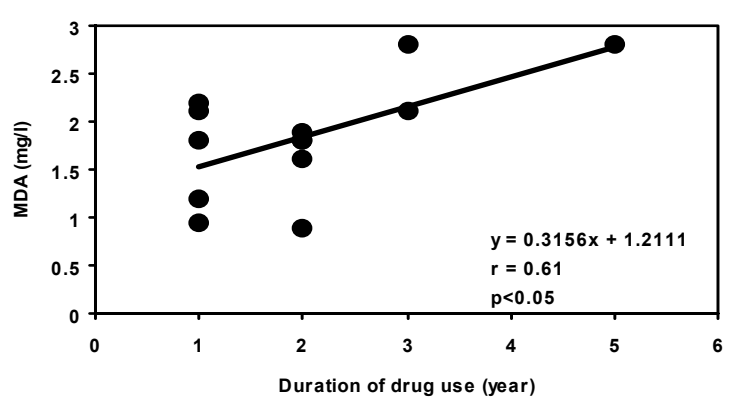

Fig. (2) Relationship between duration of illness and MDA in patients on $\mathrm{PhB}$ therapy.

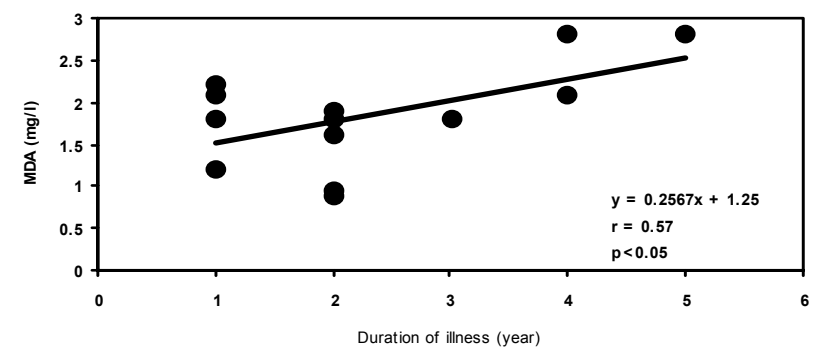

Fig. (3) Relationship between duration of drug use and MDA in patients on PhB therapy. 


\section{Discussion:}

Lipid peroxidation is a chain of reactions providing a continuous supply of free radicals $^{(7)}$ and the end products of these reactions are MDA, ethane and pentane ${ }^{(8)}$. MDA is most widely used in clinical laboratories to monitor oxidative stress and as an index of lipid peroxidation ${ }^{(9)}$.

In living systems and aerobic organisms, a complex antioxidant mechanism has been evoked to protect against free radical damage ${ }^{(10)}$. These antioxidants act together in concert to form an integrated antioxidant system $^{(11)}$, which can be classified as primary antioxidant act by preventing the formation of reactive radicals, in this class, albumin, ferritin, myoglobin and ceruloplasmin $^{(12)}$. Secondary antioxidants which act by scavenging the free radicals which already formed these cellular defense mechanisms consist of enzymatic (superoxide dismutase, glutathione peroxidase and glutathione reductase $)^{(13)}$ and non-enzymatic entities such as ascorbate, tocopherol, glutathione, uric acid, carotenoids and flavonoids ${ }^{(12)}$. The tertiary antioxidants, act by removing or repairing, damaged tissues ${ }^{(11)}$.

The mechanisms of epileptogenesis are not well established. Several studies in the last few years suggested that the body electrolytes, level of some trace elements and membrane lipid peroxidation due to increase in free radicals or decrease in activities of antioxidant defense mechanisms may be causally involved in some forms of epilepsies and also increase the recurrence of seizures ${ }^{(14,15)}$. Moreover, some antiepileptic drugs may alter free radical scavenging enzyme activities in humans and experimental animals ${ }^{(15,16)}$.

This study, demonstrated a significant increase in the serum level of MDA and a significant decrease in the serum level of TAS in all epileptic patients receiving different antiepileptic monotherapy (CBZ, VPA and PhB). This might be attributed to excess generation of metabolites, with increased body burden of free radicals added to the burden in the reported study. Mahle and Dasgupta (1997) reported that serum level of MDA in epileptic patients on phenytoin or CBZ monotherapy was significantly higher and glutathione level (representing a secondary antioxidant) was significantly lower in comparison with the control $^{(17)}$.
Ono et al (2000), concluded that some anticonvulsants (CBZ and phenytoin) can lower plasma total glutathione, reflecting treatment related oxidative stress, while its level did not differ significantly in patients treated with VPA or Ph B in comparison with controls ${ }^{(18)}$.

Yuksel and his collegues reported in 2001 that the antioxidant systems of children with epilepsy on VPA were more significantly affected than these patients on $\mathrm{CBZ}^{(19)}$. Solowiej and Sobaniec (2003) reported that serum level of MDA was significantly elevated in all epileptic patients receiving both VPA monotherapy and polytherapy, while the rise was not significant in newly diagnosed and in CBZ monotherapy ${ }^{(20)}$.

Two recent studies were conducted in 2004; the first one, carried out by Murtinenz-Ballesteros et al, they reported that there was an increased evidence of vulnerability to lipid peroxidation in adult epileptic patients on VPA ${ }^{(21)}$. The other was conducted by Bolayir et al, who studied the effects of oxcarbazepine on oxidative stress status in epileptic patients. They concluded that the value of serum MDA significantly differed from the normal subjects and pretreatment patients and that the antioxidant system of epileptic patients receiving oxcarbazepine, was significantly affected $^{(22)}$.

All published studies, regarding antioxidant status (with the exception of Mahle and Dasgapta, 1997) determine, the antioxidant status of human body by measuring antioxidant components of human separately. This study reflects the antioxidant status of human body (patients and controls), by measuring TAS serum level which can be regarded better in that, the total activity may be greater than the sum of the individual antioxidant because of cooperative interaction (23). With the exception of $\mathrm{PhB}$, this study revealed insignificant correlation between MDA and TAS serum level in epileptic patients, with the age of the patient, duration of illness and duration of monotherapy. The positive correlation between age of patients on PhB monotherapy and the decrease in TAS serum level together with the significant rise of MDA level with the duration of illness and duration of therapy can not be 
regarded as conclusive. It needs further assessment and support by future studies, owing to the small number of patients in the $\mathrm{PhB}$ group. This small number can be attributed to the shift of treatment in favour of using CBZ or VPA rather than PhB in our locality. To our knowledge, this is the first study that involves measurement of serum level of both MDA and TAS in epileptic patients on different antiepileptic monotherapy (CBZ, VPA and PhB) in comparison with the control subject, taking age of patients, duration of illness and duration of therapy in consideration.

In conclusion: Epileptic patients on CBZ, VPA or PhB monotherapy had elevated lipid peroxidation as reflected by a significant increase in serum level of MDA and a significant decrease in serum level of TAS, which might reflect a great impact on oxidative and antioxidant status.

\section{References:}

1- Hauser WA, Annegers JF, Kurland LT. Incidence of epilepsy and unprovked seizures in Rochester, Minnesota: 1935-1984. Epilepsia. (1993); 34:453468.

2- Maertens P, Dyken P, Graf W et al. Free radicals, anticonvulsants and the neuronal ceroid lipofuscinosis. Am J Med Genet. (1995); 57: 225-228.

3- Yuksel A, Cengiz $M$, Seven M,et al.. Erythrocyte glutathione, glutathione peroxidase, superoxide dismutase and serum lipid poeroxidation in epileptic children with valproate and carbamazepine monotherapy. J Basic Clin Pharmacol. (2000); 11: 73-81.

4- Verrotti $A$, Basciani $F$, Trotta $D$,et al. Serum copper, Zinc, selenium, glutathione peroxidase and superoxide dismutase levels in epileptic children before and after 1 year of sodium valproate and carbamazenine therapy. Epilepsy Res. (2002); 48: 71-75.

5- Buege JA, Aust SD. Microsomal lipid peroxidation. In: Fleischer S, Packer L editors. Methods in enzymology. Biomembranes. Part c: biological oxidations microsomal, cytochrome P450, and other hemoprotein systems.1978. New York. 52: 302-306.
6- Miller MJ,Rice Evance C, Duvies MJ et al.Total antioxidant status by colorimetric method.Clin Sci.1993;84:407-412.

7- Mayes PA .structure and function of the lipid soluble vitamins, and the pentose phosphate pathway and other pathways of hexose metabolism in: Murray RK, Granner DK, May PA and Rodwell VW editors. Harpers Biochemistry, $25^{\text {th }}$ ed .2000 . Mc GrawHill. Health professions Division. pp: 219-229; 642-682.

8- Rahman I, Macnee W. Oxidant/ antioxidant imbalance in smokers and chronic obstractive pulmonary disease. Thorax.1996; 51: 348-351.

9- Draper HH, Hadley M. Malondialdelyde determination as index of lipid peroxidation. Methods Enzymol.1990; 186; 421-431.

10- Murray RK. Metabolism of xenobiotoic and red and while blood cells. In: Murray RK, Granner DK, Mayes PA, Rodwell VW editors. Harpers biochemistry, $25^{\text {th }}$ ed .2000 . Mc GrowHill, Appleton and lange . pp: 763-768; 781-786.

11- Jacob RA. The integrated antioxidant system. Nut Res. 1995; 15:755-766.

12- Stahl W, Sies H. Antioxidant defense : vitamin $\mathrm{E}$ and $\mathrm{C}$ and Carotinods. Diabetes. 1997. 46: S14-S18.

13- Wohaieb SA, Godin PV. Starvation and related alteration in free radical tissue defense mechanism in rats. Diabetes .1987; 36:169-173.

14- Palm R, Hallmans G. Zinc and Copper metabolism in phenytoin therapy. Epilepsia. 1982; 23: 453-461.

15- Abbott LC, Nejad HH, Bottje WG et al. Glutathione levels in specific brain regions of genetically epileptic ( $\mathrm{tg} / \mathrm{tg}$ ) mice. Brain Res Bull. 1990; 52: 629631.

16- Werther $C A$, Clud $H$, Ohtake $M$ et al. Effects of long-term administration of anticonvulsants on copper, zinc and ceruloplasmin levels. Drug Nutr Interact. 1986; 4: 269-274.

17- Mahle C, Dasgupta A. Decreased total antioxidant capacity and elevated lipid hydroperoxide concentrations is sera of epileptic patients receiving phenytoin .life Sci. 1997; 61(4) :437-43. 
18- Ono H, Sakamoto A, Sakura N. Plasma total glutathione concentrations in epileptic patients taking anticonvulsants. Clin Chim. Acta .2000; 298(1-2) :135-43.

19- Yuksel A, Cengiz $M$, Seven $M$ et al. Changes in the antioxidant system in epileptic children receiving antiepileptic drugs: two-year prospective studies. J Child Neurol. 2001; 16(8): 603-6.

20- Solowiej E, Sobaniec W. The effect of antiepileptic drugs therapy on antioxidant enzyme activity and serum lipid peroxidation in young patients with epilepsy. Neurol Neurochir Pol. 2003; 37(5): 991-1003.
21- Martinez -Ballesteros C, Pita -Calandre E, Sanchez -Gonzalez $Y$ et al. lipid peroxidation in adult epileptic patients treated with valproic acid. Rev Neurol . 2004; 38(2):101-6.

22- Bolayir E, Celik K, Tas A et al. The effects of oxcarbazepine on oxidative stress in epileptic patients. Methods Find Exp Clin Pharamacol. 2004; 26(5): 345-8.

23- Maxwell SR, Thomason $H$, Sandler $D$ et al. Antioxidant status in patients with un complicated insulin dependents and noninsulin dependents diabetes mellitus. Eur J Clin Invest. 1997; 27: 484-490. 